\title{
Hereditary Anhidrotic Ectodermal Dysplasia - A case report
}

\author{
M Setu1, S K Amin², K Roy³, S M N Morshed4 \\ ${ }^{1}$ Dr. Mumtahina Setu, Assistant Professor, Department of Paediatrics, Anwer Khan Modern Medical College \\ ${ }^{2}$ Prof. Syed Khairul Amin, Professor and Head of Department, Department of Paediatrics, Anwer Khan \\ Modern Medical College \\ ${ }^{3}$ Dr. Kuntol Roy, Registrar, Department of Paediatrics, Anwer Khan Modern Medical College. \\ ${ }^{4}$ Dr. S. M. Nahid Morshed, Resident, Cardiology, Bangabandhu Sheikh Mujib Medical University
}

*Corresponding Author

\begin{abstract}
Ectodermal dysplasia is a hereditary disorder that occurs as a consequence of disturbances in the ectoderm of the developing embryo. The triad of nail dystrophy, alopecia or hypotrichosis and palmoplantar hyperkeratosis is usually accompanied by a lack of sweat glands and a partial or complete absence of primary and/or permanent dentition. Ectodermal dysplasia is a rare genetic disorder and X-linked recessive inheritance is most commonly seen. But we are reporting a rare case of autosomal recessive inheritance of Ectodermal dysplasia in here.
\end{abstract}

Key words: Ectodermal dysplasia, Anhidrotic, Prosthetics

\section{Introduction}

Ectodermal dysplasia is an extremely rare genetic disorder characterized by faulty development of ectodermal structures. The tissues in which the primary defects occur are the skin, hair, nails, exocrine glands and teeth 1 . It usually affects the males and females are the carriers. Though $\mathrm{X}$ linked recessive inheritance is most commonly seen but both autosomal recessive and autosomal dominant inheritance have been also demonstrated. The clinical features include sparse hair, abnormal or missing teeth and inability to sweat due to lack of sweat glands. One such rare case of autosomal recessive type of Ectodermal dysplasia is presented here. The etiology of ectodermal dysplasia appears to be genetic in nature 2 . X-linked recessive inheritance is more commonly seen. But we are reporting a rare case of autosomal recessive inheritance of Ectodermal dysplasia here.

\section{Case Report}

A 2 years old boy presented to us with the complaint of increased body temperature \& heat intolerance since birth. Mother also gave history of no sweating since birth and deformed \& delayed eruption of teeth. There was no history of consanguineous marriage between the parents. On examination, he had dry skin and hyper pigmented \& wrinkled area in periocular \& perioral region with sparse hair on the body and scalp. Hair were fine in texture \& light in colour. Prominent supraorbital ridges \& depressed nasal bridge were also present. Both upper \& lower eyelids showed sparse eyelashes. The skin was warm \& dry. Intra oral examination revealed only two teeth which were dystrophied \& conical in shape and the lips were prominent. He had no nail dystrophy.

The similar findings were present in his younger sister who was only 7 months old. Based on these findings a diagnosis of hereditary ectodermal dysplasia was done. Patient was referred to department of Dentistry for dental advices. Parents were counselled about the origin, nature, course and prognosis of the disease. 
Hereditary Anhidrotic Ectodermal Dysplasia - A case report

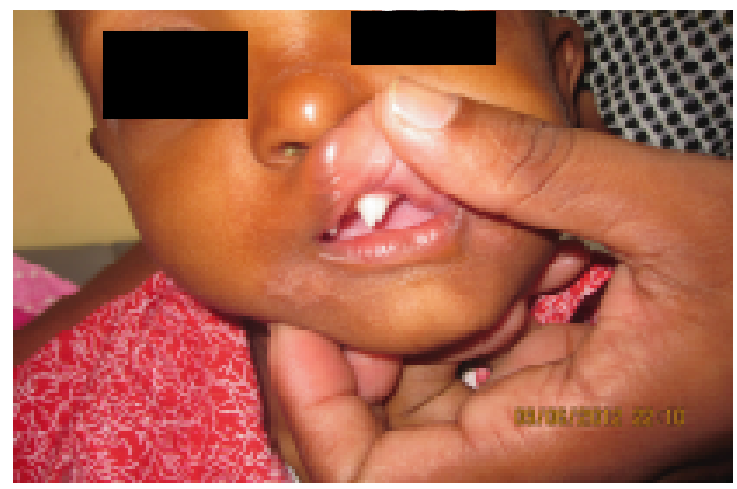

Fig. 1: The teeth were reduced in number and conical in shape

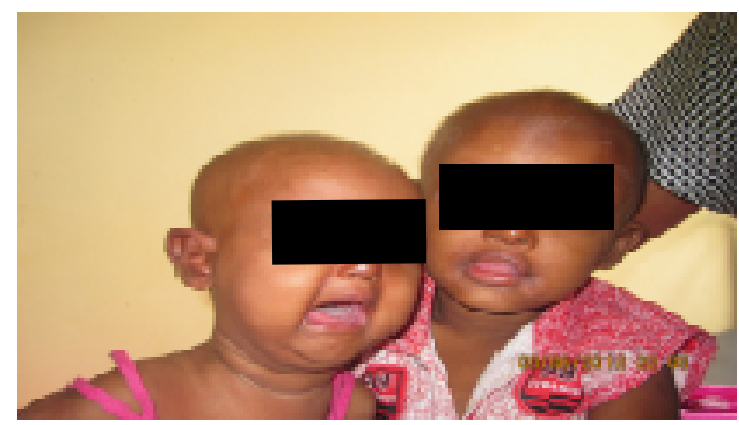

Fig. 2: Sparse scalp hair, eyebrows \& eyelashes, depressed nasal bridge and perioral hyperpigmentation was evident in the boy $\&$ his younger sister.

\section{Discussion}

The Ectodermal dysplasia are a group of inherited disorder that share in common developmental defects involving at least two of the major structure classically hold to derive from the embryonic ectoderms hair, teeth, nails, sweat glands ${ }^{3}$. The incidence of ectodermal dysplasia in males is estimated at 1 in 100,000 births 4 . Thurman first described this entity in $1848^{5}$. More than 192 distinct disorders have been described till date. Freire Maia and Pinherio published an exhaustive review and classification system for these disorders using a numeric system of 1 (hair), 2 (teeth), 3 (nail), 4 (sweat glands) for characterization6. X-linked recessive inheritance of Ectodermal Dysplasia is most common. Here, the complete syndrome does not occur in females but females may show dental defects, sparse hair, reduced sweating and dermatoglyphic abnormalities 3 . But in autosomal recessive variety both male \& female can show the characteristic findings of Ectodermal Dysplasia. The major concern seen in these patients is the lack of teeth and the special appearance, as seen in our case 2 . The most characteristic finding is the reduced number and abnormal shape of teeth. The delay in eruption of teeth is often the first step in diagnosis. The men have an easily recognizable facies, also referred to as an old man facies. Some infants have a premature look with scaling of the skin. This can also form a clue to the diagnosis ${ }^{2}$. The extra oral features seen in this disorder are frontal bossing with the forehead appearing square in shape, prominent supra orbital ridge, depressed nasal bridge (saddle nose) ${ }^{8}$. The other features include midface hypoplasia, pointed chin and protruberent and everted lips as seen in our case 8 . Abnormalities of skin, nails and teeth are also noted which was also seen in our case ${ }^{3}$. Prenatal diagnosis of ectodermal dysplasia has occasionally been reported which has been diagnosed by 20 weeks gestation ${ }^{9}$. The characteristic facies is pathognomic but may not be recognized in infancy. In partial forms, the pointed conical teeth provide the most valuable indication and should suggest the need for sweat test and a skin biopsy ${ }^{3}$. Both autosomal dominant and recessive mode of inheritance has been described. In our case, parents were not affected but both their son and daughter was suffering from Ectodermal Dysplasia. This is a rare example of autosomal recessive variety of the disease. Another variety of hydrotic ectodermal dysplasia called as Clouston syndrome is inherited in an autosomal dominant manner was described by Clouston in 1929 and Lowrey et al in 1966, which is found in Canadian families of French descent. This syndrome usually spares the sweat glands 9 .

The defective sweating in this disease prevents adequate thermal regulation and predispose to hyperpyrexia. Febrile seizures, brain damage and death in early life may result from exposure to hot environments 10 . Our patient also gives history of heat intolerance. Dental treatment is often necessary in patients with some forms of ectodermal dysplasia and some children may need dentures as early as 2 years of age 11 . It is important to seek dental advice early as maintenance of the alveolar ridge is important for later dental intervention12,13,14. Prosthetics teeth are implanted in adult life for mastication and speech. Importantly, aesthetic dental interventions 
in patients with ectodermal dysplasia and malformed teeth and malocclusion helps with the development of a positive self-image and overall oral health $12-16$. The treatment usually comprises of complete restoration of function and aesthetics normalise the vertical dimension and provide adequate support to the facial soft tissues.

\section{Conclusion}

Ectodermal dysplasia is a rare genetic disorder with involvement of various tissues in the body. Autosomal recessive inheritance of Ectodermal Dysplasia is also very rarely seen as seen in our case. A careful and a thorough examination will lead to an accurate diagnosis. Restoration of normal function should be the main concern in these patients.

\section{References}

1. Virginia PS, Fitzpatrick TB, Eisen AZ, et al. Ectodermal dysplasias. 6th ed. Newyork: Mc Graw Hill, 2003; 1: 515-522.

2. Mortier K, Wackens G. Ectodermal Dysplasia anhidrotic. Orphanet Encyclopedia. 2004:1-6.

3. TM Anoop, S Simi, PN Mini, et al. Hypohydrotic Ectodermal Dysplasia, JAPI, 2008; 268-270.

4. Stevenson AC, Kerr CB. On the distribution of the frequencies of mutation to genes determining harmful traits in man. Mutat Res 1967; 4: 339-52.

5. Neopane A, Singh SK, Manandhar B. Hypohidrotic ectodermal dysplasia. Kathmandu University Medical Journal 2006; 1: 520-521.

6. Freire - Maia, Pinheiro M. Ectodermal Dysplasias: A clinical classification and a causal review. Am J Med Genet. Nov 1994; 53(2): 153-62.

7. Johnson ER, Roberts MW, Guckes AD, et al. Analysis of craniofacial development in children with hypohidrotic ectodermal dysplasia. Am. J. Med. Genet 2002; 112: 327-34.
8. Bergendal B, Koch G, Kurol J, et al. Consensus conference on ectodermal dysplasia with special reference to dental treatment. The Institute for Postgraduate Dental Education, Jonkoping, Sweden 1998.

9. Richard AS, KarinV, Gerard K, et al. Placement of an endosseous implant in a growing child with ectodermal dysplasia. Oral Surg Oct Med Oral Pathol 1993; 75: 69-73.

10. Drago RP, Ehrenreich T. Ectodermal dysplasia anhidrotic type and prolonged fever in an infant. New York State Journal of Medicine $1961 ; 61: 2473$.

11. Yenisey M, Guler A, Unal U. Orthodontic and prosthodontic treatment of ectodermal dysplasia case report. Br Dent J 2004; 196: 677-9.

12. Freiman A, Borsuk D, Barankin B, et al. Dental manifestations of dermatologic conditions. J Am Acad Dermatol. 2008 Nov 21.

13. Yavuz I, Z Baskan, R Ulku, et al. "Ectodermal Dysplasia: Retrospective study of 15 cases". Archives of Medical Research 2006; 37: 403409.

14. Yavuz I, S Kiralp, Z Baskan. "Hypohidrotic Ectodermal Dysplasia: A Case Report". Qinttessence International 2008; 39: 81-86.

15. Ohno K, Ohmori I. Anodontia with hypohidrotic ectodermal dysplasia in a young female: a case report. Pediatr Dent 2000; 22: 49-52.

16. M Yildirim, MF Oktay, C Ozmen, et al. "Reveal By Biotechnological Equipment to The Bilateral Nonfunctional Submandibular Glands in ectodermal Dysplasia". Biotechnol \& Biotechnol. Eq 2008; 22: 1005-1007. 